\title{
CONHECIMENTO “SEM MAIS" E A QUESTÃO DO PRINCÍPIO DA CIÊNCIA NOS SEGUNDOS ANALÍTICOS DE ARISTÓTELES
}

\author{
Alexandre Guedes Barbosa ${ }^{1}$
}

\section{Resumo:}

Aristóteles inicia o livro dos Segundos Analíticos afirmando que a relação inerente ao ensino/aprendizagem é oriunda de um conhecimento prévio. Também, diz que o conhecimento científico demonstrativo, ao possibilitar um conhecimento sem mais, escapa da dificuldade presente no Mênon, de Platão. Basicamente, essa aporia expressa a impossibilidade de se conhecer, de fato, algo, uma vez que, ao se assumir um dos seguintes dois pontos de partida, nos perceberemos sem saída: 1) a ignorância: se não se sabe algo, como buscar conhecê-lo? Ou, se ao encontrá-lo, como saber se isso era o que se estava a procurar? 2) conhecimento prévio: se se conhece previamente algo, podemos chamar de conhecimento aquilo que se alcança à medida que já sabíamos? Pelo fato de Aristóteles, além de estar consciente da aporia do Mênon, indicar o conhecimento científico demonstrativo como livre da problemática do Diálogo de Platão, buscaremos neste artigo compreender, tanto o que é o conhecimento sem mais nos Segundos Analíticos, como, em que medida, ele, partindo de um conhecimento prévio, supera a aporia supracitada. Veremos que é razoável afirmar que na demonstração de um silogismo obtemos um certo tipo de conhecimento, muito embora isto não seja suficiente para sanar as dúvidas e os impasses que surgem do próprio fundamento desse conhecimento científico por demonstração.

Palavras-chave: Conhecimento. Demonstração. Princípios. Aristóteles. Platão.

\section{KNOWLEDGE "WITHOUT MORE" AND THE QUESTION OF PRINCIPLE OF SCIENCE IN ARISTOTLE'S POSTERIOR ANALYTICS}

\begin{abstract}
:
Aristotle starts the book of Posterior Analytics stating that the inherent relationship to teaching/learning comes from prior knowledge. Also, he says that demonstrative scientific knowledge, by enabling knowledge without more, escapes the difficulty present in Plato's Meno. Basically, this aporia expresses the impossibility of knowing, in fact, something since by assuming one of the following two points of starting, we will perceive ourselves as having no way out: 1) ignorance: if someone do not know something, how to seek to know it? Or, finding it, how to know if it is what we were looking for? 2) Prior knowledge: if someone already know something in advance, can we call knowledge what is achieved once we already knew it? Because Aristotle, in addition to being aware of the aporia of the Meno, indicates demonstrative scientific knowledge as free from the problems of Plato's Dialogue, we will seek, in this paper, to understand both what is the knowledge without more in the Posterior Analytics and, as to what extent, starting from a previous knowledge, it surpasses the aforementioned aporia. We will see that is reasonable to affirm that in the demonstration of a syllogism we obtain a certain type of the knowledge, although this is not enough to resolve the doubts and impasses that arise from the very foundation of that scientific knowledge by demonstration.
\end{abstract}

Keywords: Knowledge. Demonstration. Principles. Aristotle. Plato.

\section{Introdução}

Aristóteles inicia o primeiro livro dos Segundos Analíticos, mais especificamente em 71a, afirmando que toda a relação entre ensino e aprendizagem

\footnotetext{
1 Bacharel, mestre e doutorando em Filosofia pela Universidade Federal de Goiás (UFG). E-mail:
} guedestayor@hotmail.com. http://orcid.org/0000-0002-2444-6053 
advém de conhecimento prévio. Em $71^{\mathrm{a}} 17$, diz que o vir a conhecer se dá por meio de um conhecimento anterior de certos itens necessários, como os universais, a partir dos quais é possível adquirir novo conhecimento, tanto pelo modo silogístico, quanto pela indução. ${ }^{2}$ Enquanto o conhecimento silogístico é caracterizado pela demonstração argumentativa que toma por base premissas gerais, válidas, verdadeiras e universais, pelas quais, dada a necessidade do termo médio, isto é, da premissa imediata e necessária, se pode concluir um raciocínio de forma verdadeira, rigorosa e necessária, na indução, por sua vez, temos um conhecimento que, partindo da percepção e do entendimento de algo particular, por uma via dialética, ou seja, pela investigação que parte de uma opinião com pretensão de ser verdadeira, cuja validade é posta em cheque pelos argumentos usados, se chegaria a um conhecimento geral, e aplicável a todos os casos.

Nos Segundos Analíticos, apesar da referência a outras formas possíveis de conhecimento, o objetivo maior de Aristóteles com seu tratado é apresentar o conhecimento científico demonstrativo, capaz de nos fornecer um conhecimento "sem mais", sem o qual, certamente, de acordo com o estagirita, cairíamos na dificuldade do Mênon. ${ }^{3}$ O filósofo faz referência à aporia presente no Diálogo de Platão, da qual falaremos mais à frente. Mas, a título de introdução, podemos, de modo geral, dizer que ela expressa a impossibilidade de se conhecer, de fato, algo, uma vez que, ao se assumir um dos seguintes dois pontos de partida, nos perceberemos sem saída: 1) a ignorância: se não se sabe algo, como buscar conhecê-lo? ou, se ao encontrá-lo, como saber se isso era o que se estava a procurar? 2) conhecimento prévio: se se conhece previamente algo, podemos chamar de conhecimento aquilo que se alcança à medida que já sabíamos?

Como pode ser percebido, Aristóteles, ao dizer que todo ensinamento e aprendizado requer um conhecimento prévio e que o conhecimento científico demonstrativo escapa à dificuldade imposta por Mênon, se compromete com a superação dessa aporia. Em outras palavras, Aristóteles se compromete em dizer que há ganho de conhecimento, mesmo quando já se conhece, anteriormente, algo.

Partindo disso, pretendemos, com o entendimento do que vem a ser o conhecimento sem mais, compreender de que maneira obtemos conhecimento de algo que não sabíamos, mesmo partindo de algo que já se sabe.

\footnotetext{
${ }^{2}$ Cf. ARISTÓTELES, 2004a, p. 13.

${ }^{3}$ Cf. ARISTÓTELES, 2004a, p. 14, 71a 17. 
Quanto ao método adotado neste trabalho, queremos salientar que foi intencional o enquadramento e a restrição da questão nos Segundos Analíticos, uma vez que os problemas relacionados à aquisição dos primeiros princípios (conhecimento prévio), sendo um dos problemas mais difíceis como ressalta Porchat ${ }^{4}$, naturalmente demande a análise de outras obras de Aristóteles. Todavia, nosso procedimento não deixará de, eventualmente, indicar as passagens relacionadas, tanto a esse tema, quanto a outros, sejam eles por meio das palavras de Aristóteles, ou por meio das palavras de seus estudiosos, desde que sejam pertinentes ao nosso escopo.

Através disso, veremos que, por mais que o tratado aristotélico, por um lado, seja suficientemente claro quanto ao conhecimento científico por demonstração proporcionar um ganho de conhecimento em relação à explicação causal, por outro, não é suficiente para resolver, de modo peremptório, as questões sobre o método de aquisição dos primeiros princípios, nem para que se estabeleça, de forma completamente pertinente à Aristóteles, divisões dogmáticas relacionadas às atividades do intelecto no processo de conhecimento em geral.

\section{A aporia do Mênon e o conhecimento sem mais.}

A aporia da qual Aristóteles faz alusão está no Mênon, uma das obras de Platão classificadas como Diálogos. Essa aporia vem à tona por meio de um tema anterior, posto por Mênon a Sócrates, que investiga se a virtude é algo que se ensina. ${ }^{5}$ Sócrates, à sua maneira, redireciona o tema. Com efeito, mostra a necessidade de, antes, buscar a definição de virtude em sua essência para, assim, entendê-la de modo geral. Somente dessa maneira, seria possível se obter uma compreensão da virtude a qual possa ser aplicada a todos os casos e não somente às situações específicas. Com isso, se percebem em dificuldades, pois só conseguem chegar a exemplos da virtude em casos pontuais, como o caso da virtude do homem, da mulher, da criança, do ancião. Isto é, apenas alcançam uma compreensão restrita às ações atreladas a um fato, a uma ação, ou a uma idade determinada, mas não de modo absoluto. ${ }^{6}$

4 Cf. PORCHAT, 2004, p. 143.

5 70a: "Podes dizer-me, Sócrates a virtude é coisa que se ensina? Ou não é coisa que se ensina mas que se adquire pelo exercício? Ou nem coisa que se adquire pelo exercício nem coisa que se aprende, mas algo que advém aos homens por natureza ou por alguma outra maneira? (PLATÃO, 2010, p. 19)

6 Cf. PLATÃO, 2010, p. 23, 71e- 72a.

\begin{tabular}{|l|l|l|l|l|}
\hline Qenista Dialectus & Ano 10 & n. 23 & Maio - Agosto 2021 & p. $54-65$ \\
\hline
\end{tabular}


Com a dificuldade da definição da virtude, Mênon identifica um impasse quanto à aquisição de conhecimento. Em 80d, ele diz a Sócrates:

E de que modo procurarás, Sócrates, aquilo que não sabes absolutamente o que é? Pois procurarás propondo-te <procurar> que tipo de coisa, entre as coisas que não conheces? Ou, ainda que, no melhor dos casos, a encontres, como saberás que isso <que encontraste> é aquilo que não conhecias? (PLATÃO, 2010, p. 81).

Por mais que o que tenha, por assim dizer, ascendido a chama de tal problema tenha sido a questão sobre a definição da virtude, tema mais voltado para o âmbito do conhecimento prático voltado às ações político éticas, a questão sobre a impossibilidade de conhecimento é que ganha notoriedade. Pois, em verdade, como é possível obter conhecimento quando: 1) não se sabe o que se procura; ou 2) se procura o que já se sabe? Sócrates não reconhece nisso um bom argumento e recorre ao argumento da imortalidade da alma $^{7}$ para sair desse impasse.

$\mathrm{O}$ argumento da imortalidade da alma, grosso modo, também admite que a alma pode nascer várias vezes sem, contudo, perecer. A partir disso, Sócrates entende que o conhecimento seria o mesmo que um rememorar, uma vez que a alma, tendo visto todas as coisas, seja no mundo sensível, seja no mundo supralunar, reconheceria o que antes já tivera contato. $^{8}$

Dada a especificidade do contexto platônico da aporia, não prosseguiremos com o desdobrar do argumento de Sócrates, pois, caso contrário, não conseguiríamos voltar a referência que Aristóteles faz em $71^{\mathrm{a}}$, onde diz que a dificuldade do Mênon decorre da ausência de um conhecimento "sem mais". Mas o que significa esta expressão “conhecer sem mais”? De acordo com ele, é o conhecimento da causa pela qual certa coisa é, e que não pode ser de outro modo.

[71b 9] Julgamos conhecer cientificamente uma coisa qualquer, sem mais (e não do modo sofístico, por concomitância), quando julgamos reconhecer, a respeito da causa pela qual a coisa é, que ela é causa disso, e que não é possível ser de outro modo. É evidente que conhecer cientificamente é algo deste tipo; pois tanto os que não conhecem julgam estar assim dispostos, como também os que conhecem assim se dispõem de fato; por conseguinte, é impossível que seja de outro modo aquilo de que, sem mais, há conhecimento científico. (ARISTÓTELES, 2004a, p. 15).

${ }^{7}$ Cf. PLATÃO, 2010, p. 51, 81b-c.
${ }^{8}$ Cf. PLATÃO, 2010, p. 53, 81d. 
Aristóteles, com isso, não descarta a existência de outros possíveis modos de conhecimento. Até mesmo, como pode ser percebido, faz referência ao conhecimento sofístico em oposição ao conhecimento sem mais. De todo modo, o que parece ser o compromisso diretriz nos Analíticos é delimitar o que vem a ser um conhecimento por demonstração, por silogismo científico.

[71b 16] Se há também um outro modo de conhecer cientificamente, investigaremos depois, mas afirmamos que de fato conhecemos através de demonstração. E por "demonstração" entendo silogismo científico; e por "científico" entendo aquele segundo o qual conhecemos cientificamente por possuí-lo. (ARISTÓTELES, 2004a, p. 15).

Tal conhecimento deve partir, segundo Aristóteles, de "[...] itens verdadeiros, primeiros, imediatos, mais cognoscíveis que a conclusão, anteriores a ela e que sejam causas dela. [...]" (ARISTÓTELES, 2004a, p. 15, 71b19). São itens verdadeiros e necessários, uma vez que não se pode conhecer cientificamente sem que tais e tais coisas não sejam o caso. Por exemplo, não se pode conhecer de modo geométrico, e sem ser o caso, que a diagonal é comensurável ( 71 b 25), ou que o triângulo, por exemplo, não tenha três lados. É o caso que eles sejam isso $\left(71^{\mathrm{a}} 11\right)$. Ademais, são primeiros e imediatos, pois as demonstrações não devem ser compreendidas como pertencentes a uma cadeia infinita. A demonstração deve partir necessariamente de princípios que são o caso, anteriores a conclusão e, por isso, mais cognoscíveis que ela.

Tomemos um exemplo mais emblemático usado por Aristóteles nos Analíticos para elucidar este ponto. Como podemos demonstrar que o isósceles tem dois ângulos retos? Se para uma demonstração devemos partir de itens verdadeiros, princípios universais mais cognoscíveis que a conclusão, qual seria o princípio desse silogismo? $\mathrm{O}$ universal $^{9}$ "ter 2 ângulos retos" que, ao ser atribuído necessariamente ao sujeito "triângulo", nos fornece a premissa maior: todo triângulo tem $2 \mathrm{R}$. De certa forma, a definição de triângulo pode ser entendida como um universal, pois a compreensão que a figura geométrica de três lados é um triângulo é anterior e mais cognoscível que a compreensão de que isósceles tem três lados. Quer dizer, o triângulo não tem três lados

9 Angioni ressalta que o uso dos universais nos Segundos Analíticos é bem peculiar em relação a outras obras do estagirita. CF. ANGIONI, s/d, p. 332. Todavia, para os fins deste trabalho, estamos nos referindo a sua compreensão estrita de "predicação geral".

\begin{tabular}{|c|c|c|c|c|}
\hline Qevista Dialectus & Ano 10 & n. 23 & Maio - Agosto 2021 & p. $54-65$ \\
\hline
\end{tabular}


porque é um isósceles, mas, ao contrário, isósceles, por ter três lados, é compreendido como sendo um triângulo. Destarte, a partir da premissa: todo triangulo têm $2 R$, captamos a premissa menor: o isósceles é um triângulo, logo, concluímos e podemos demonstrar que o isósceles tem a soma de seu ângulos internos igual a dois ângulos retos. ${ }^{10}$

Resumindo. A demonstração de que um triângulo isósceles possui a soma de seus ângulos internos equivalente a dois ângulos retos deve partir da compreensão universal de que ter $2 \mathrm{R}$ (dois ângulos retos) é o caso de ser atribuído ao sujeito triângulo, um conceito mais geral que comporta a essência dos outros tipos de triângulos. Desta maneira, quando partimos da compreensão de que, necessariamente, todo triângulo tem $2 \mathrm{R}$ e que isósceles é um triangulo, concluímos, e temos a possibilidade de demonstrar, que, necessariamente, isósceles tem $2 \mathrm{R}$. Neste caso, temos um conhecimento sem mais, ou seja, temos a demonstração causal, isto é, do por que o isósceles tem $2 \mathrm{R}$, não podendo ser de outro modo.

De modo geral, esta é a estrutura da demonstração do conhecimento científico: premissa maior e universal, premissa menor e imediata, de onde se segue a conclusão por via de demonstração da causa necessária, ou seja, do por que tal coisa é e não pode ser de outro modo.

Ao longo dos Segundos Analíticos, Aristóteles desdobra várias aplicações dessa estrutura geral e, em cada caso específico, surgem problemas pontuais no sentido da adequação de determinado conhecimento à estrutura silogística demonstrativa. No entanto, a apresentação e a aplicação do conhecimento sem mais não elimina as questões fundamentais a respeito do conhecimento prévio aludido em $71 \mathrm{~b} 19$, nem mesmo fornece o conhecimento do modo como são apreendidos tanto os universais, quanto as premissas imediatas de um silogismo. A próxima seção, será dedicada a essas questões. Veremos o que pode ser entendido nos Segundos Analíticos com relação a elas.

\section{Questões sobre o princípio da ciência}

Em 100b 5, Aristóteles faz uma intrigante alusão à inteligência como sendo o princípio da ciência, por ser mais verdadeira e por fornecer mais conhecimento dos princípios em comparação com as demonstrações:

10 Cf. $73 b 32$.

\begin{tabular}{|l|l|l|l|l|}
\hline Qonita Dialectus & Ano 10 & n. 23 & Maio - Agosto 2021 & p. 54-65 \\
\hline
\end{tabular}


[100b 5-16] [...] uma vez que nenhum outro gênero é mais exato que a ciência, a não ser a inteligência, e que os princípios propiciam mais conhecimento do que as demonstrações, e que toda ciência se dá com raciocínio, dos princípios não há ciência, mas, visto que não é possível haver nada mais verdadeiro que a ciência, a não ser a inteligência dos princípios - para os que consideram isso e que o princípio da demonstração não é demonstração, de modo que ne, o princípio da ciência é ciência. Pois bem: se não dispomos de nenhum outro gênero verdadeiro além da ciência, é a inteligência que é princípio da ciência; E o princípio é do princípio, ao passo que a ciência, em seu todo, se tem semelhante com relação ao assinto em seu todo. (ARISTÓTELES, 2004b, p. $85)$.

Há, portanto, segundo Aristóteles, inteligência dos princípios e não ciência, uma vez que toda ciência é constituída pelo raciocínio, e a inteligência não pode ser pensada através desse, por assim dizer, método. Essa passagem indica claramente que há diferença entre raciocínio e inteligência.

Num outro estudo ${ }^{11}$, vimos a referência ao mesmo contraste entre raciocínio e inteligência, à época, em Ética a Nicômaco. ${ }^{12} \mathrm{Na}$ ocasião, ao investigar a diferença entre razão e intelecto em Aristóteles, mais especificamente, a diferença entre dianóia e nous, $\mathrm{o}$ artigo de James Lesher, The meaning of nous in the Posterior Analytics, foi de extrema relevância. Por ele, chegamos a concluir que o nous (intelecto), seria a evidência necessária para a busca (dianóia - atividade racional) de conhecimento. Ou seja, a cada novo conhecimento em ato, teríamos um, por assim dizer, novo nous que, por sua vez, seria a base para a atividade racional - dianóia - um conhecimento em potência, ainda em processo. Isto teria a ver com o que chamamos de "[...] unidade fundamental do processo cognitivo, no qual cada ponto de partida já é um ponto de chegada e cada ponto de chegada não é senão um novo ponto de partida." (GUEDES, 2015, pp. 73-74).

Essa conclusão advém do entendimento que Lesher tem da função ampla do nous a partir dos Segundos Analíticos, sobretudo, em sua relação com o universal. De fato, ao lermos o texto de Aristóteles, não há grandes dificuldades em compreender que o universal pode ser entendido como um princípio, seja ele próprio, ou comum. Sendo a inteligência a apreensão dos princípios, ela, então, teria a ver, em última análise, com os universais.

11 GUEDES, A. O conceito de nous e sua relação com o conceito de dianoia no pensamento de Aristóteles. In: Inquietude, vol. 06, $\mathrm{n}^{\text {0 }}$ 02, p. 52-74, Goiânia, jul/dez 2015.

12 Cf. GUEDES, 2015, p. 56.

\begin{tabular}{|c|l|l|l|l|}
\hline Q & Ano 10 & n. 23 & Maio - Agosto 2021 & p. 54 - 65 \\
\hline
\end{tabular}


Nos capítulos 9 e 10, Aristóteles diz sobre a diferença entre os princípios os quais podem ser próprios, ou comuns. Princípios próprios são os relativos a determinados campos do conhecimento, como, por exemplo, a unidade, na matemática, e a grandeza, na geometria. Os princípios comuns, ou axiomas comuns, são os mais gerais e, por isso, dão suporte às demonstrações e às definições. Isto é, são os que, tirando a especificidade - unidade, ou grandeza - podem ser percebidos como fundamento em outras áreas do saber. Este seria o caso do princípio de não contradição, ou princípio de identidade. ${ }^{13}$ Sua generalidade permite a evidência, por exemplo, de que o triângulo é tal que não pode ser confundido com o círculo, bem como, que a unidade não pode ser entendida, de modo absoluto, como sendo a parte.

Neste sentido, parece que os princípios próprios e os comuns, assim como os universais e as premissas imediatas estão submetidos à atividade intelectual em geral, uma vez que dependem de um princípio mais geral, como o de não contradição. Por isso, não é impertinente entendermos que há nous com relação a tais princípios, não obstante haver diferenças entre o modo de apreensão dos mesmos.

Nesta esteira, Lesher indica passagens nos Analíticos pelas quais se pode entender o nous como apreensão dos princípios também pelo modo indutivo. De fato, em 88 3-14 e 100b1, vemos que os universais podem ser entendidos como que adquiridos pelo repetido números de percepções (LESHER, 1973, pp. 51-53). ${ }^{14}$ Isso implica que a atividade do nous não pode ser somente compreendida como uma apreensão imediata independente da experiência, uma espécie de conhecimento a priori. A função do intelecto, como reforça Lesher, admite uma construção pela via sensível, uma vez que o universal surge como o resultado de variadas percepções.

Além disso, Lesher indica que a tradução de Ross e outros de 88 b33 não demarca a diferença presente entre nous, episteme e episteme indemonstrável; algo que favorece o entendimento de que o nous não é somente uma episteme indemonstrável. ${ }^{15}$ Tal diferença parece ter sido observada nas traduções de Barnes ${ }^{16}$ e Angioni, onde vemos,

${ }^{13}$ Cf. Met. $996 b 1-997^{\mathrm{a}} 15$.

14 “[...] And it is this progression which I think is present in Aristotle's mind when at 100b1 ff. he describes the process in which perception produces the universal and speaks of a 'stop' at the species of animal, and next at animal, and finally a stop when the unitary universals are reached [...] (LESHER, 1973, p. $62)$.

15 Cf. LESHER, 1973, p. 54.

16 Apesar de Barnes não traduzir por intelecto, mas por compreensão: “[...] Nor is comprehension concerned with them (by comprehension I mean a principle of understanding), nor indemonstrable understanding (this is belief in an immediate proposition). [...]" (BARNES, 1993, p. 45).

\begin{tabular}{|l|l|l|l|l|}
\hline Qovista Dialectus & Ano 10 & n. 23 & Maio - Agosto 2021 & p. $54-65$ \\
\hline
\end{tabular}


em 88b35, que, por inteligência deve se entender princípio de conhecimento científico e, por conhecimento indemonstrável, a concepção de uma premissa imediata. ${ }^{17}$

Todavia, acredito que Lesher, com isso, queira dizer que não temos nous no conhecimento indemonstrável, porque isso seria incoerente, tanto com sua proposta de pensá-lo de modo amplo, como incoerente com o próprio Aristóteles, uma vez que afirma, categoricamente, que os primeiros princípios são indemonstráveis e deles temos inteligência. Mas vejo que Lesher com isso quer identificar uma certa diferença metodológica entre a inteligência e o seu caráter indemonstrável presente num mesmo ato. Ou seja, a compreensão do nous pode admitir um processo indutivo, quando se trata dos universais, assim como pode admitir um processo intuitivo, quando for o caso da apreensão das premissas imediatas. Isso pode ser compreendido em uma visão ampla do conceito de intelecto, na qual

[...] a relação entre o nous e a indução (epagoge) seria esta: há uma atividade, apreensão do princípio universal; falar desta atividade como ato da noesis é dar uma caracterização epistemologica, ao passo que falar de indução é falar metodologicamente. [...] (GUEDES, 2015, p. 66). ${ }^{18}$

Porém, como bem observa Lesher, há trechos controversos nos Analíticos com relação a, por assim dizer, uma certa valoração entre a ciência e a inteligência. Apesar de Aristóteles em 100b 5 dizer que a inteligência é mais exata que a ciência, em 88a5-8 diz que a compreensão do universal é mais precisa que a intuição. Levando ao entendimento que o conhecimento/episteme, é mais valioso que a intuição intelectual (noiésis) (1973, pp. 53-54).

Além disso, a afirmação quanto ao método de aquisição dos universais por indução não está isenta de problemas. Porchat ressalta a dificuldade entre as passagens 100b3-4 e 100b14-16, onde a primeira diz ser a indução (epagogé) a competência de apreensão dos primeiros princípios, ao passo que a segunda diz ser a intuição intelectual (nous) a responsável.

Quanto a essa questão, assim como Porchat, Zingano identifica, no problema expresso pelo binômio indução-intuição, a necessidade de investigação sobre a

17 Cf. ARISTÓTELES, 2004a, p. 71.

18 “[...] Intuição e indução não respondem à mesma questão, tampouco estão em conflito. [...]” (ZINGANO, 2004, p. 29).

\begin{tabular}{|l|l|l|l|l|}
\hline Qonita Q Dialectus & Ano 10 & n. 23 & Maio - Agosto 2021 & p. $54-65$ \\
\hline
\end{tabular}


dialética $^{19}$, um modo de argumentação dialógico no qual se toma como ponto de partida proposições com pretensão de serem verdadeiras, isto é, opiniões (ta endoxa). O sentido do método dialético é revelar, após a rigorosa depuração argumentativa, a verdade, o que significa negar, ou afirmar a, então, opinião tomada como ponto de partida. Deste modo, “[...] como a dialética pode discorrer sobre tudo, apoiando-se nas opiniões aceitas, nesta medida ela pode contribuir para a aquisição dos princípios. [...]” (ZINGANO, 2004, p. 29).

Mas, apesar de concordarem que o problema entre a indução e a intuição no processo de aquisição dos princípios aponta para a investigação da dialética em Aristóteles, discordam em suas traduções da passagem 101 b3-4 de Tóp. I, 2, mais especificamente do trecho hodòn ékhei, que diz respeito à dialética. Na interpretação de Zingano, a dialética tem a ver com a aquisição dos primeiros princípios, ao passo que Porchat diz que a dialética é o caminho para a aquisição dos primeiros princípios. ${ }^{20}$

Não pretendemos nos aprofundar nessa investigação, o que significa dizer, não trataremos da dialética aqui, pois, como vimos, isso nos levaria a outros textos de Aristóteles e nossa intenção é entender a relação do conhecimento prévio e do conhecimento sem mais em referência à aporia do Mênon nos Segundos Analíticos. Contudo, é importante perceber que a questão da aquisição dos princípios, como ressalta Zingano, é um dos problemas mais difíceis em Aristóteles, ${ }^{21}$ e por isso, não temos como resolver - se é que existe solução para tal problema - somente com a leitura dos Analíticos.

Por fim, salientamos que toda a dificuldade envolvendo a atividade do nous não compromete a proposta de Lesher em pensá-lo nos Analíticos como aquisição dos universais pela indução. Ao contrário, com seu estudo, Lesher colabora, ao indicar uma via de ação ligada à sensibilidade, para a abertura necessária dos horizontes investigativos necessários para a compreensão imparcial da atividade do intelecto em sua plenitude. Com isso, podemos nos desviar de conclusões precipitadas, o que, dada a magnitude do pensamento de Aristóteles e das questões que ele enfrenta, pode ser compreendido como um bom resultado.

19 Cf. PORCHAT, 2004, p. 145.

${ }^{20}$ Cf. PORCHAT, 2004, p. 147.

${ }^{21}$ Cf. PORCHAT, 2004, p. 143.

\begin{tabular}{|l|l|l|l|l|}
\hline Qovista Oialectus & Ano 10 & n. 23 & Maio - Agosto 2021 & p. $54-65$ \\
\hline
\end{tabular}




\section{Conclusão}

Portanto, podemos dizer que o conhecimento sem mais é o conhecimento que demonstra a causa necessária de um certo juízo expresso na conclusão. Também podemos dizer que, de acordo com Aristóteles, quem não possuir [...] explicação do por que, sendo possível uma demonstração, não possui conhecimento [...]. (ARISTÓTELES, 2004a, p. $25) .^{22}$

Quanto ao conhecimento prévio, entendemos que seu âmbito ultrapassa a esfera do conhecimento científico. Em Metafísica 1005 20-25, Aristóteles nomeia este âmbito como sendo a ciência do filósofo, ou a Filosofia Primeira, que se dedica na investigação das causas primeiras e dos axiomas, tema que não é propriamente dos Analíticos. $^{23}$

Neste sentido, ao que parece, a ciência está limitada por sua própria essência. Quer dizer, sendo constituída pelo discurso racional, não tem autonomia para dizer sobre seus princípios, ou sobre o seu fundamento. Nesse caso, a investigação deixa de ser científica, passando a ser filosófica, ou metafísica, como passou a ser entendida pela tradição. Mas talvez este julgamento seja precipitado, ou mesmo, parcial, pois, como vimos, não temos como afirmar indubitavelmente que o método intelectual seja totalmente diferente do método científico, uma vez que, ao que tudo indica, ambos fazem o uso da dialética.

Por fim, com relação à aporia do Mênon, parece ser razoável depreender que podemos conhecer algo previamente e, ainda assim, obter conhecimento de algo que não sabíamos; esta é a relação do universal com a demonstração. Quer dizer, podemos conhecer o universal e, ao mesmo tempo, não saber demonstrar algo a partir dele. Assim, ao aprender a demonstrar o porquê de algo ser necessariamente o que é, adquirimos conhecimento de algo que não sabíamos, mesmo que este conhecer não trate de conteúdo, mas apenas da forma; uma diferença entre ontologia e epistemologia, respectivamente.

\section{Referências}

${ }^{22}$ Cf. 74b 26-28.

23 " [...] Mas não esqueçamos que o estudo dos axiomas cabe fundamentalmente à filosofia primeira e não está entre os temas principais do tratado sobre a ciência, embora eles sejam e tenham de ser frequentemente mencionados, sobretudo nos capítulos iniciais do livro I, em virtude de sua função estruturadora de todo saber dianoético, consequentemente também do saber demonstrativo. [...]" (PORCHAT, 2004b, p. 226).

\begin{tabular}{|c|l|l|l|l|}
\hline Qovista Dialectus & Ano 10 & n. 23 & Maio - Agosto 2021 & p. $54-65$ \\
\hline
\end{tabular}


ANGIONI, L. Conhecimento e opinião em Aristóteles (Segundos Analíticos 1.33), s/d, GT - Aristóteles, Unicamp, pp. 329-341.

ARISTÓTELES. Metafísica. Trad. Edson Bini, Edipro, 2012.

Posterior analytics. Trad. Jonathan Barnes, Clarendon Press, Oxford, 1993.

Segundos analíticos, Livro I. Trad. Lucas Angioni, Clássicos da Filosofia: Cadernos de Tradução, nº 7, UNICAMP, 2004a.

Segundos analíticos, Livro II. Trad. Lucas Angioni, Clássicos da Filosofia: Cadernos de Tradução, n ${ }^{\circ}$, UNICAMP, 2004 b.

GUEDES, A. O conceito de nous e sua relação com o conceito de dianoia no pensamento de Aristóteles. In: Inquietude, vol. 06, nº 02, p. 52-74, Goiânia, jul/dez 2015.

LESHER, J.H., The Meaning of NOY $\Sigma$ in the Posterior Analytics. In: Phronesis, Vol. 18, No 1, pp. 44-68, 1973.

PLATÃO. Teeteto. Trad. Adriana Manuela Nogueira e Marcelo Boeri, Fundação Calouste Gulbenkian, Lisboa, 2010.

PORCHAT, O. Sobre a doutrina aristotélica dos princípios das ciências, Réplica a Francis Wolff. In: Analytica, V. 8, nº1, 2004b, pp. $189-238$.

. Voltando à dialética de Aristóteles, réplica a Marco Zingano. In: Analytica, V . 8, nº1, 2004, p. 143.

ZINGANO, M. Dialética, indução e na aquisição dos primeiros princípios. In: Analytica, V. $8, \mathrm{n}^{\circ} 1,2004$, pp. 27-41. 